\title{
Energy Efficiency Research of BIPV System in Partial Shading Condition
}

\author{
Mingfei Wei ${ }^{1, a}$ Huiqin Wang ${ }^{1}$ Li Jiang $^{1}$ Fang Yang ${ }^{1}$ \\ ${ }^{1}$ School of Information and Control, Xi'an University of Architecture and Technology, \\ Xi'an , shannxi 710055 ,China \\ awmf1974@126.com
}

Key Words: the building integrated photovoltaic, partial shading, energy conversion structure, energy efficiency

\begin{abstract}
In the building integrated photovoltaic (BIPV) system, the influence of partial shading on the energy efficiency of the BIPV system is large in certain circumstance. Energy efficiency of the centralized system and multi string type system are researched in four typical shading conditions. Results show that, when the shading is not serious, whether the system is in weak light or bright light condition, the energy conversion efficiency of the centralized system and multi string system is high and the difference is small. When the shading is serious, whether the system is in weak light or bright light condition, the system energy efficiency difference of two kinds of energy conversion structure is very big. In general, multi string systems is more higher than centralized system in energy efficiency, so the choice of a better energy conversion structure is the key factor to reduce the shading effect and improve the system energy efficiency.
\end{abstract}

\section{Introduction}

Photovoltaic system with different energy conversion structure, its energy efficiency is related to photovoltaic array, maximum power point of photovoltaic module, maximum power voltage, the converter input voltage range and so on, so that the main factors of influencing the system efficiency include environmental conditions, electrical parameters and the converter input voltage range ${ }^{[1-2]}$.

In many influence factors, the partial shading is the key factor of influence on many photovoltaic systems, but the research in this area is relatively less ${ }^{[3-4]}$. For example, in building integrated photovoltaic (BIPV) system, photovoltaic modules are usually mounted on the surface of the building, are influenced by the partial shading from the surrounding buildings, trees and other things, those reduce the system energy efficiency ${ }^{[5]}$. So it is very important to study the effect of partial shading.

\section{The premise conditions of system energy efficiency assessment in partial shading}

To simplify the analysis, without considering the impact of photovoltaic modules temperature, and photovoltaic modules as minimum shading cell, electrical parameters of the electrochemical cell as shown in Table $1 . I_{\mathrm{ph} 0}$ is light generated current, $I_{\mathrm{s} 1}$ and $A_{1}$ are the reverse saturation current and the quality factor of diode $\mathrm{D}_{1}, I_{\mathrm{s} 2}$ and $A_{2}$ are the reverse saturation current and the quality factor of diode $\mathrm{D}_{2}$.

Table 1 Photovoltaic cell parameters

\begin{tabular}{clll}
\hline parameter & value & parameter & value \\
\hline$I_{\mathrm{ph} 0}$ & $5.12 \mathrm{~A}$ & $R_{\mathrm{sh}}$ & $683 \Omega$ \\
$I_{\mathrm{s} 1}$ & $2.66 \times 10^{-6} \mathrm{~A}$ & $R_{\mathrm{s}}$ & $7.8 \times 10^{-3} \Omega$ \\
$A_{1}$ & 1.86 & $V_{b r}$ & $18 \mathrm{~V}$ \\
$I_{\mathrm{s} 1}$ & $1.89 \times 10^{-6} \mathrm{~A}$ & $\alpha$ & $2.1 \times 10^{-3} \Omega$ \\
$A_{2}$ & 1.24 & $n n$ & 3 \\
\hline
\end{tabular}


The light intensity in front of shelter is set to $1000 \mathrm{~W} / \mathrm{m} 2$. The number of photovoltaic modules in variety of system is 24 , and the parameters of photovoltaic modules are same. All the converters efficiency are set to $100 \%$ in the system. The input voltage range is shown in table 2 . Four kinds of typical shading conditions(the A, B, C and D) in the analysis are considered, and are used to simulate the bright light and shading problem not serious, bright light and shading problem serious, weak light and shading not serious, weak light and shading serious.

Table 2 The input voltage range of system

\begin{tabular}{ccc}
\hline system cass & input voltage $(\mathrm{v})$ & note \\
\hline centralized system & $300-550$ & single-stage inverter \\
multi string system & $150-600$ & two-stage inverter \\
\hline
\end{tabular}

\section{System efficiency evaluation}

In partial shading condition of A, specific shading distribution of two groups photovoltaic modules is shown in table 3 . The partial shading condition simulates that system is in bright light condition (such as sunny) and shading problem is not serious. As can be seen from table 3, only a handful of photovoltaic modules are located in the shadings, and no full shading ( $\mathrm{S}=100 \%)$ module.

Table 3 The shading of photovoltaic modules in the condition of A

\begin{tabular}{|l|l|l|l|l|l|l|l|l|l|l|l|l|}
\hline $\mathrm{S}$ & 01 & 02 & 03 & 04 & 05 & 06 & 07 & 08 & 09 & 10 & 11 & 12 \\
\hline $\mathrm{I}$ & 0.82 & 0.61 & 0.00 & 0.00 & 0.00 & 0.00 & 0.00 & 0.00 & 0.00 & 0.00 & 0.00 & 0.00 \\
\hline $\mathrm{II}$ & 0.80 & 0.58 & 0.59 & 0.00 & 0.00 & 0.00 & 0.00 & 0.00 & 0.00 & 0.00 & 0.00 & 0.00 \\
\hline
\end{tabular}

In the partial shading condition, the efficiency evaluation of two groups energy conversion structures is shown in Fig. 1. The P-V characteristics of centralized and multi string system is shown in (a), energy efficiency comparison chart of the two kinds of system is shown in (b). In the partial shading condition, all the photovoltaic modules can output the maximum power of $5600 \mathrm{~W}$. At this time, photovoltaic array output P-V characteristic curve of the centralized and multi string system exist many extreme value points. Fig. 1 shows that, when the shading is not serious, energy efficiency of different system is relatively high, and the difference is not big.

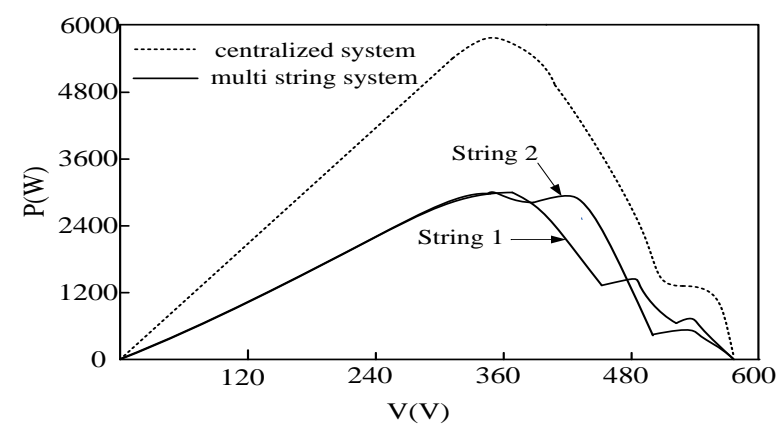

(a) P-V curve

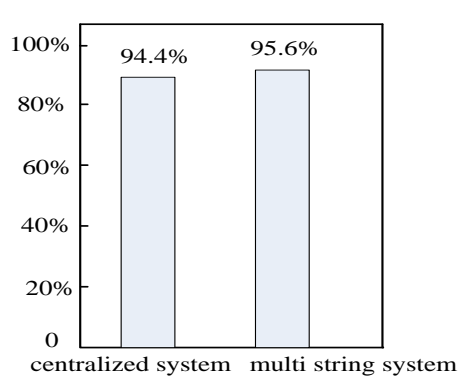

(b) Comparison of energy efficiency

Fig. 1 Evaluation of different system energy efficiency in condition of A

In partial shading condition of $\mathrm{B}$, specific shading distribution of two groups photovoltaic modules is shown in table 4. The partial shading condition simulates that system is in bright light condition (such as sunny) and shading problem is serious. As can be seen from table 4, a plurality of photovoltaic modules are located in the shadings, and there are 3 complete shading $(S=100 \%)$ modules.

Table 4 The shading of photovoltaic modules in the condition of B

\begin{tabular}{|l|l|l|l|l|l|l|l|l|l|l|l|l|}
\hline S & 01 & 02 & 03 & 04 & 05 & 06 & 07 & 08 & 09 & 10 & 11 & 12 \\
\hline I & 1.00 & 1.00 & 0.53 & 0.48 & 0.22 & 0.16 & 0.00 & 0.00 & 0.00 & 0.00 & 0.00 & 0.00 \\
\hline II & 0.99 & 1.00 & 0.59 & 0.52 & 0.21 & 0.15 & 0.00 & 0.00 & 0.00 & 0.00 & 0.00 & 0.00 \\
\hline
\end{tabular}


In the partial shading condition, the efficiency evaluation of two groups energy conversion structures is shown in Fig. 2. The P-V characteristics of centralized and multi string system is shown in (a), energy efficiency comparison chart of the two kinds of system is shown in (b). In the partial shading condition, all the photovoltaic modules can output the maximum power of $4186 \mathrm{~W}$. At this time, photovoltaic array output P-V characteristic curve of the centralized and multi string system exist many extreme value points. Energy efficiency of the centralized system is only 33.8\%. Fig. 2 shows that, when the shading is serious and system is in bright light condition, energy efficiency is more obvious differences between two systems.

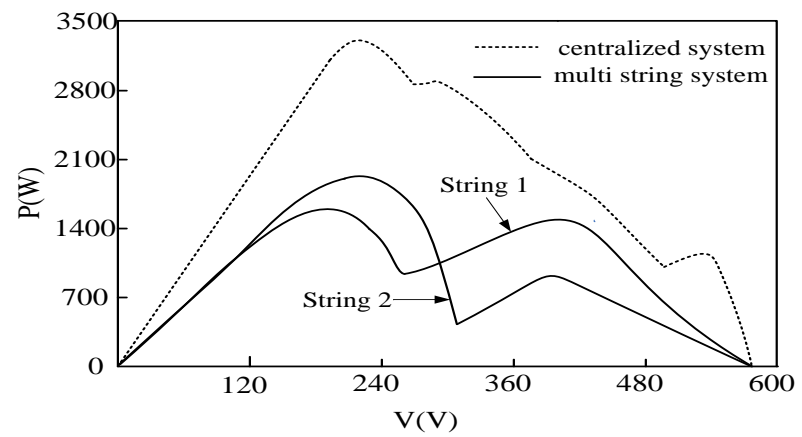

(a) P-V curve

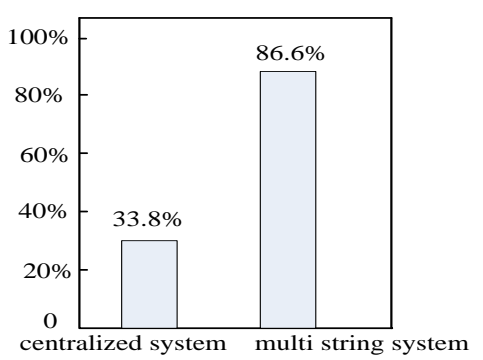

(b) Comparison of energy efficiency

Fig. 2 Evaluation of different system energy efficiency in condition of B

In partial shading conditions of $\mathrm{C}$, specific shading distribution of two groups photovoltaic modules is shown in table 5 . The partial shading condition simulates that system is in weak light condition (such as the morning, evening or cloudy day etc.) and shading problem is not serious. As can be seen from table 5, only a handful of photovoltaic modules are located in the shading, and no full shading ( $\mathrm{S}=100 \%)$ module.

Table 5 The shading of photovoltaic modules in the condition of C

\begin{tabular}{|l|l|l|l|l|l|l|l|l|l|l|l|l|}
\hline $\mathrm{S}$ & 01 & 02 & 03 & 04 & 05 & 06 & 07 & 08 & 09 & 10 & 11 & 12 \\
\hline $\mathrm{I}$ & 0.95 & 0.92 & 0.92 & 0.94 & 0.90 & 0.82 & 0.82 & 0.82 & 0.82 & 0.82 & 0.82 & 0.82 \\
\hline $\mathrm{II}$ & 0.95 & 0.92 & 0.92 & 0.90 & 0.90 & 0.88 & 0.82 & 0.82 & 0.82 & 0.82 & 0.82 & 0.82 \\
\hline
\end{tabular}

In the partial shading condition, the efficiency evaluation of two groups energy conversion structures is shown in Fig. 3. The P-V characteristics of centralized and multi string system is shown in (a), energy efficiency comparison chart of the two kinds of system is shown in (b). In the partial shading condition, all the photovoltaic modules can output the maximum power of $1050 \mathrm{~W}$. At this time, photovoltaic array output P-V characteristic curve of the centralized and multi string system exist many extreme value points. Fig. 3 shows that, when the shading is not serious, weak light condition is similar to the bright light condition (partial shading A), energy efficiency of two systems is relatively high, and the difference is not big.

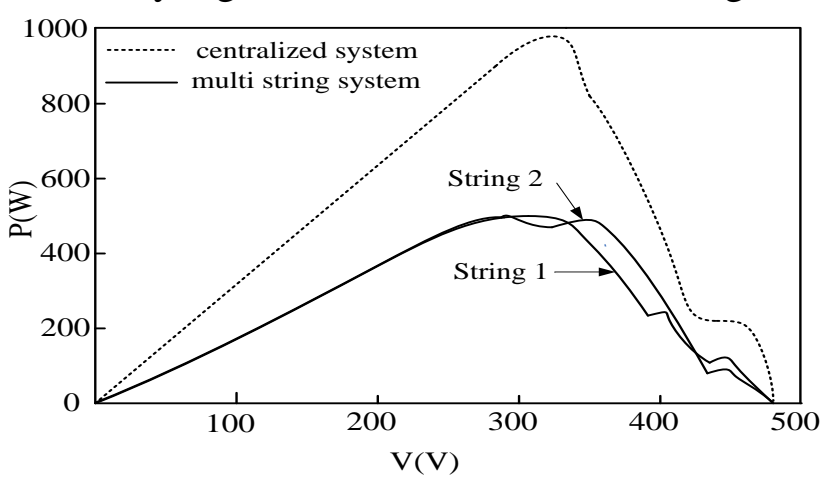

(a) P-V curve

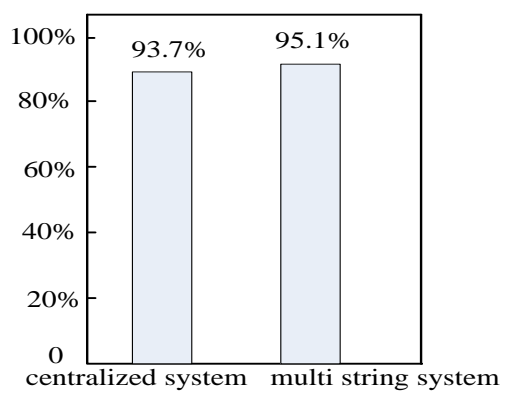

(b) Comparison of energy efficiency

Fig. 3 Evaluation of different system energy efficiency in condition of C 
In partial shading conditions of $\mathrm{D}$, specific shading distribution of two groups photovoltaic modules is shown in table 6. The partial shading condition simulates that system is in weak light condition and shading problem is serious. As can be seen from table 6, a plurality of photovoltaic modules are located in the shadings, and there are 3 complete shading ( $S=100 \%)$ modules.

Table 6 The shading of photovoltaic modules in the condition of $\mathrm{D}$

\begin{tabular}{|l|l|l|l|l|l|l|l|l|l|l|l|l|}
\hline $\mathrm{S}$ & 01 & 02 & 03 & 04 & 05 & 06 & 07 & 08 & 09 & 10 & 11 & 12 \\
\hline $\mathrm{I}$ & 1.00 & 0.90 & 0.90 & 0.90 & 0.82 & 0.82 & 0.82 & 0.82 & 0.82 & 0.82 & 0.82 & 0.82 \\
\hline $\mathrm{II}$ & 1.00 & 1.00 & 0.90 & 0.90 & 0.82 & 0.82 & 0.82 & 0.82 & 0.82 & 0.82 & 0.82 & 0.82 \\
\hline
\end{tabular}

In the partial shading condition $\mathrm{D}$, the efficiency evaluation of two groups energy conversion structures is shown in Fig. 4. The P-V characteristics of centralized and multi string system is shown in (a), energy efficiency comparison chart of the two kinds of system is shown in (b). All the photovoltaic modules can output the maximum power of $781 \mathrm{~W}$. At this time, output P-V characteristic curve of the centralized and multi string system exist many extreme value points. Centralized system energy efficiency is only 31.7\%. Fig. 4 shows that, when the shading is serious and the system is in bright light condition, weak light condition is similar to the bright light condition (partial shading condition B), energy efficiency is more obvious difference between the various systems.

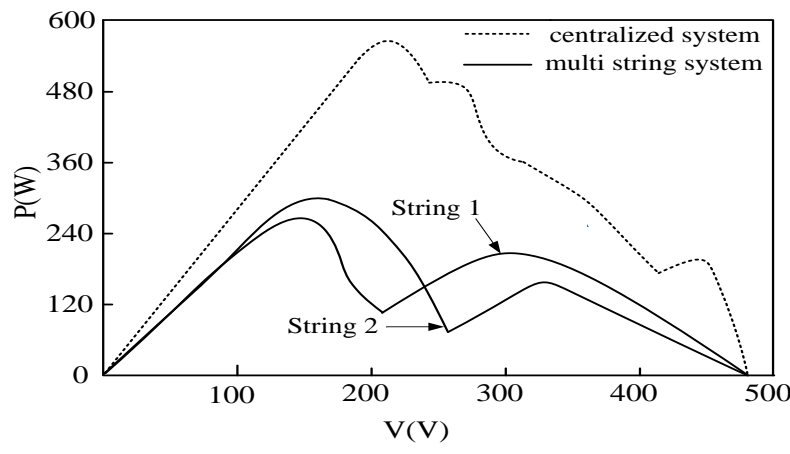

(a) P-V curve

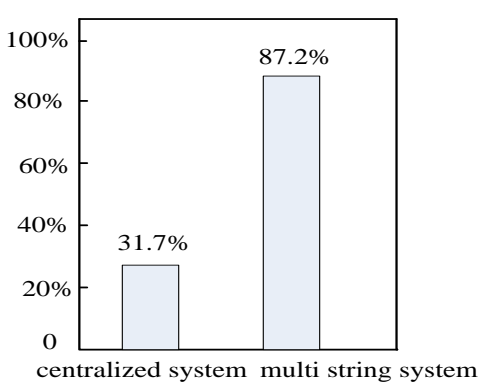

(b) Comparison of energy efficiency

Fig. 4 Evaluation of different system energy efficiency in condition of D

\section{Conclusion}

Whether the system is in weak light or bright light condition, when shading problem is not serious, the system energy conversion efficiency of all kinds of energy conversion structures are not very different and high relatively. When the shading problems more serious, whether the system is in weak light or bright light condition, the system energy conversion efficiency of all kinds of energy conversion structure varies widely. In each case, multiple string system is higher than centralized system in efficiency.

\section{Acknowledgements}

This work was financially Supported by Foundation Education Department of Shaanxi Province (Grant No. 15JK1432)

\section{References}

[1] Y. Shen, A. Luo, Y. D. Chen. Power System Technology. Vol.38(2014), p.1449

[2] S. Tsani, Z. Stela. Energy Economics. Vol.32(2010), p. 582

[3] B. Liu, S. Duan, T. Cai. Solar Energy. Vol.86(2012) , p.482

[4] K. Kobayashi. IEEE Power Engineering Society General Meeting. Vol.4(2009), p.2612

[5] T. Noguchi, S. Togashi. IEEE Transactions Industrial Electronics. Vol. 49(2012), p.217 